\title{
Regional Business Confidence as Early Indicator of Regional Economic Growth
}

Ewert Kleynhans

North-West University, South Africa

ewert.kleynhans@nwu.ac.za

Clive Coetzee

North-West University, South Africa

ecoreports@gmail.com

Official sub-national GDP figures in South Africa are usually published with long delays or not at all, i.e. relevant, reliable, and real-time economic data on a provincial and local (municipal) level are often non-existent, causing a significant data asymmetry at the sub-national level. The search for an 'optimal' sub-national proxy for regional economic growth focuses on the possible use of regional business confidence. This article, therefore, investigates the use of regional business confidence indices (R B CI) as an early indicator or proxy of the regional economic growth rate (RGDP). To this end, the study employed panel cointegration methodology and techniques to interrogate the possible association between regional business confidence and regional economic growth, focusing on three specific regions of KwaZulu-Natal, South Africa. The results suggest that the utilisation of regional business confidence indicators indeed has merit. Constraints experienced in the study indicate the direction that further studies may follow, especially concerning the scope of the period and crosssections. The research, therefore, addresses a fundamental gap in the data asymmetry in South Africa, while also setting a benchmark for other researchers to follow.

Key Words: business confidence, gross regional product, economic growth, panel data econometrics, fixed effects, random effects, GDP, BCI JEL Classification: C23, C53, E01, E17, O11

(c))BY-SA https://doi.org/10.26493/1854-6935.19.27-48

\section{Introduction}

This article investigates the potential use and/or application of confidence indicators, especially business confidence indicators, to proxy economic activity, at the sub-national level in South Africa. This is relevant since upto-date knowledge and relevant data concerning the state of the national, provincial, and local economy are of utmost importance to conduct eco- 
nomic analysis and policy formulation (Mitchell et al. 2005; Gossman and Hayes 2018). Unfortunately, in South Africa (s A), like many other developing countries, such data of the sub-national economy are in most cases only available with significant time delays of up to one to two years, if available at all.

The gross domestic product (GDP) is generally used as the appropriate indicator representing economic activity and should be available at a subregional level (Porter 2003). However, in SA, Statistics South Africa (Stats SA) only publishes provincial GDP data with a one-year lag, while not publishing any municipal GDP data at all. To this end, two private sector companies do publish provincial and municipal GDP data, but also with at least a one-year lag. Also, given that the private sector data are not deemed to be official data, it complicates the use of such data, especially for policymaking.

On the other hand, the demand for sub-national economic analysis has substantially increased over the past number of years, especially since sub-national governments (provincial and municipal authorities) have taken on greater responsibilities regarding economic development and growth. It seems evidently counterproductive to use national data for sub-national economic analysis and policymaking, except for setting the scene and national overview.

This disjuncture between the demand and supply for sub-national data makes it important and relevant for the search and assessment of viable proxies that can be used with some confidence and reliability in subnational economic analysis and policymaking. One such proxy is business confidence since, according to the European Central Bank (всв), during the past years, indicators on business confidence or sentiment and its ability to monitor and forecast short-term economic developments have emerged (European Central Bank 2003).

The empirical relationship between business confidence indicators and economic output at the sub-national level is explored in this article to determine whether business confidence indices might be employed as an early indicator of regional gross domestic product (GDP), using data of the urban regions of KwaZulu-Natal (K ZN), South Africa.

This article commences by studying some relevant empirical work already published, mainly from the $\mathrm{ECB}$, but also others. Against that background, a business confidence index series and an economic growth rate series for each of three provincial regions are developed, followed by evaluating the panel. Thirdly, the article focuses on the application of panel 
data econometric and ARDL techniques to empirically test and evaluate the relationship between regional business confidence and regional economic growth rates.

\section{Literature Overview of Existing Research}

As stated by De Mello and Figueiredo (2014), a relevant empirical question is whether confidence indices (including business confidence) contain any piece of relevant information about the current/future behaviour of the level/rate of growth of economic activity. To this end, Curtin (2000) argues that this particular topic has been under debate since the release of the first confidence surveys. While there seemingly is no consensus in the literature, according to Dées and Brinca (2013), most authors find a statistically significant relationship between measures of confidence and the current and future behaviour of economic variables, for example, Mourogane and Roma (2003), Ludvigson (2004) and Wilcox (2007) for the Us, Kwan and Cotsomitis (2006) for Canada, as well as Easaw and Heravi (2004).

Santero and Westerlund (1996) examined the usefulness of consumer and business surveys in assessing the cyclical position of the economy and for forecasting output movements. The study included eleven Organization for Economic Cooperation and Development (OECD) countries between 1980 and 1995 following a panel data methodology. In the main, the study found that sentiment measures obtained from business surveys provide valuable information for the assessment of the economic situation and forecasting. However, the relationship between sentiment indicators and output varies considerably across countries and sentiment measures. The study also found that the results of the Granger tests suggest that business sentiment indicators in most countries contain relevant information for the prediction of output, in particular when measured by industrial production.

The ECB studied the possibility of using statistics on confidence to estimate GDP, using the Ес B Economic Sentiment Indicator (ESI) and their Industrial Confidence Indicator (ICI) (European Central Bank 2003). Their analysis included the six largest euro countries (in terms of GDP) and estimated their relationship between the confidence indicators and the real economy of each country.

The use of a bottom-up or country-specific approach is deemed appropriate when country-specific shocks occurred in the period under investigation and data are available on a country level on a deeper his- 
torical basis (Gossman and Hayes 2018). The Ес в model constructed by Mourougane and Roma $(2003,519)$, for the individual euro area countries, is displayed in equations 1 and 2.

$$
\begin{aligned}
\Delta \ln \mathrm{GDP}_{t} & =[\mathrm{I} \Delta \mathrm{INDIC}] \times\left[\begin{array}{c}
A_{t} \\
\Gamma_{t}
\end{array}\right]+w_{t}=[\mathrm{I} \Delta \mathrm{INDIC}] \times \beta_{t}+w_{t}, \\
\beta_{t} & =\beta_{t-1}+s_{t} .
\end{aligned}
$$

A measurement equation (equation 1), where the real GDP growth rate is a function of the variation in the confidence indicator, forms the essence of the model. The vector of coefficients of the system $\left(\beta_{t}\right)$ is determined by a transition equation (equation 2). A random walk process $\left(\beta_{t-1}+s_{t}\right)$ is assumed for the transition equation. Equation 2 disappears when the parameters are assumed to be constant over time. Equation 1 then takes the form of a basic linear function relating the variation of confidence indicators and real GDP growth rates. The expected Gamma $(\Gamma)$ should be positive, implying that an increase in confidence will translate into higher GDP growth. The error terms $w$ and $s$ are white noise orthogonal vectors.

The Есв central bank applies Granger causality tests between the GDP growth rates (in real terms) and confidence indicators (in first difference format). The results suggest that, except for Spain, the ICI indicator Granger causes real GDP and that the reverse causations do not hold for any of the countries. The results suggest the usefulness of the ICI and its lagged values in explaining real GDP growth. Regarding the ESI, i.e. ESI Granger causing real GDP, for all countries except Spain, the Е С s states that the results are encouraging as a preliminary sign of the utility of confidence indicators.

The вс в concluded that the results demonstrate that confidence indicators could indeed be practical in estimating and forecasting real shortterm GDP growth rates. There are, however, some ambiguities in the results, for example in the case of Spain, which suggest that confidence indicators are not perfect. It is therefore not guaranteed that the results suggest uniformity over countries and therefore country-specific characteristics need to be considered.

The всв followed up their research and focused on predicting real economic growth for the euro area in the short term, applying vintage data. Numerous monthly indicators (including confidence indicators), individually and in combinations, were used. The selection was guided not by selecting the 'best' combination of monthly indicators, but rather 
determined by its merits, investigating its pseudo-real-time and comparing it to actual figures and establishing the estimation's rigour and quantifying the comparative significance of identified forecast errors of the inputs. Three attributes of significance are how close the variables and GDP growth are related, the scope of the revisions, and its timeliness (European Central Bank 2006).

Equation 3 estimates the relationship between GDP growth (in real terms) and confidence as proxied by the Есв Sentiment Indicator (ESI).

$$
\mathrm{d} \log (\mathrm{GDP})=\alpha_{\mathrm{O}}+\alpha_{1} \times \mathrm{ESI}+\alpha_{2} \times \mathrm{d} \log (\mathrm{GDP}(-1)) .
$$

A major benefit of equation 3 , according to the $\mathrm{ECB}$, is parsimony, while the ad-hoc weight assignment among the different confidence indicators within the ESI is seen as a cause of concern. The various sectoral confidence indicators were also considered separately.

Equation 4 includes sectoral business confidence indicators of manufacturing (MAN_CONF), construction, retail trade and other services (SER_CONF). Confidence indicators of construction and retail trade were excluded because of their very high levels of volatility (Diron 2008). The equation can be written as:

$$
\mathrm{d} \log (\mathrm{GDP})=\alpha_{\mathrm{O}}+\alpha_{1} \times \mathrm{d}(\text { MAN_CONF })+\alpha_{2} \times \text { SER_CONF. }
$$

Binette and Chang (2013) state several challenges when forecasting real short-term GDP growth. Given the large volume of data, it takes time, and specific instruments must be developed to handle various time intervals and deal with truncated data, which resulted from the redefinitions of variables. In response to these challenges, the Bank of Canada developed a single-factor dynamic model estimating Canada's Short-Term Indicator (CSI). This is published monthly and based on the assumptions that a data series consists of two components, namely the common and an idiosyncratic part. Both these common and individual dynamics components, as described by autoregressive (A R) processes, are used to estimate the indicators of the csi.

Two sets of criteria were used in the choice of indicators to construct the CSI (Binette and Chang 2013). Firstly, there should be a direct link between the variables and the Canadian economy, and secondly, the historic forecasts had to be superior to those already published in the existing literature. The CsI includes 32 indicators, such as the volume of retail trade, housing and total hours worked. It included financial data and international variables, as well as soft information including consumer confidence. The csi model performs generally as anticipated according to the Bank of Canada. The study also found that the accuracy 
of the CSI increases as more information becomes available. The views expressed by the Bank of Canada on the usefulness of confidence indicators are supported by both the Bank of Latvia (Benkovskis 2008) and the Bank of Albania (2018), stating that the choice of a monthly indicator should be based on its timeliness and relevance to GDP. It should also be based on sound theoretical and economic rationale. To this end, business sentiment or confidence is one such monthly indicator that fulfils these criteria. The Banks state that the results of their estimation models are statistically rigid.

With relevance to South Africa, Binge (2020) states that business confidence indicators are widely used leading indicators of economic activity. Binge uses the microdata from the Bureau for Economic Research (BER) business tendency surveys to create new composite indicators of business confidence for South Africa. These surveys usually contain a small number of qualitative questions. Indicators are derived from the subjective answers to questions on past, current, and future developments. The assumption is that agents form opinions about economic conditions before a specific business activity is implemented. These opinions may be called 'confidence.'

The relationship is investigated for the aggregate variables, as well as separately for each sector, using bivariate recursive VARs featuring a measure of confidence and real GDP growth (Binge 2020). In the bivariate VAR, both variables are treated as endogenous:

$$
\begin{aligned}
& y_{t}=\beta_{10}-\beta_{12} z_{t}+\gamma_{11} y_{t-1}+\gamma_{12} z_{t-1}+\varepsilon y_{t}, \\
& z_{t}=\beta_{2 \mathrm{O}}-\beta_{21} y_{t}+\gamma_{21} y_{t-1}+\gamma_{22} z_{t-1}+\varepsilon z_{t},
\end{aligned}
$$

where $y$ is the output, $z$ is the confidence indicator, and qvarepsilon is the residual of each equation. According to Binge, the results, in general, provided evidence at least of significant co-movement between the sectoral and aggregate confidence indicators and real economic activity. The indicators had a positive and significant impact on real GDP growth in the VAR models. Shocks to the indicators accounted for a sizeable fraction of variation in economic activity.

\section{The Data}

The choice of regions (3 regions) and years ( 11 periods) is purely by default. The three regions were included on the basis that at the conception stage of the regional business confidence project, they had functioning 
chambers of commerce with sufficient memberships. The regions were expanded to include three more regions, but only at a much later stage; unfortunately, too late to include in this study in that the associated period only covers the latter four years, i.e. 2012 to 2015. The regional business confidence project only started in 2005 because of funding availability and lasted until 2015 when the funding ended. At the conception stage, the regional business confidence project was planned to incrementally expand to around eight regions and become self-financed, therefore continuing as long as the need exists. However, this, unfortunately, did not materialise, hence the limited panel data set, which is not ideal for a study of this nature. Notwithstanding the limitations of the panel data set, it still holds some value in that it can be used for exploratory purposes with the caveat that further research still needs to be done to further test and verify the methods and results.

REGIONAL GROSS DOMESTIC PRODUCT AND GROWTH RATES

The regional gross domestic product (GDP) for each of the three regions studied in the current study is estimated using a national, provincial and regional structure model. The model uses national gross domestic product estimates as published by Statistics South Africa (http://www.statssa .gov.za) to estimate the gross domestic product for each of the three regions. The model is quite similar to models used by IHs Global Insight (https://www.ihsmarkit.co.za/Products/ReX) and Quantec in their regional economic estimates.

To estimate the gross domestic product of each region, the study utilised a national disaggregation methodology (see Rossouw 2017). Aggregate indicators are transformed to disaggregate indicators using a related series, for example, the gross domestic product of each region was estimated using analogous regional and national indicators (Coetzee and Kleynhans 2017). These disaggregated data are, however, only used in this study to test the various models. Once the model is accepted, it would be used as an instrument to estimate economic activity. Chow-Lin's (1971) approach supports this methodology, i.e. disaggregated regional data can be estimated when only the fully observed aggregated data are available (Vidoli and Mazziotta 2012; Polasek 2009).

The base year for the model is determined by updating the latest available regional level GDP data published by Statistics South Africa from the release date of November 1994 to the start of the model in 2015. This is done by estimating the structural relationships from various na- 
TABLE 1 Fuel Consumption Structure (As a \% of National)

\begin{tabular}{lrrrrrrrr}
\hline Region & 2008 & 2009 & 2010 & 2011 & 2012 & 2013 & 2014 & 2015 \\
\hline eThekwini & 9.68 & 9.58 & 8.64 & 9.77 & 10.99 & 10.77 & 10.08 & 9.75 \\
Msunduzi & 1.16 & 1.29 & 1.29 & 1.36 & 1.32 & 1.39 & 1.35 & 1.58 \\
uMthlatuze & 1.09 & 0.96 & 0.91 & 0.89 & 0.87 & 0.91 & 0.84 & 0.74 \\
\hline
\end{tabular}

NOTES Authors' calculations based on data from Department of Energy (https://www .gov.za/department-energy-m).

TABLE 2 Growth Rates of Regional Gross Domestic Product (\%)

\begin{tabular}{lrrrrrrrrrrr}
\hline Region & 2005 & 2006 & 2007 & 2008 & 2009 & 2010 & 2011 & 2012 & 2013 & 2014 & 2015 \\
\hline Msunduzi & 5.66 & 5.36 & 6.10 & 2.28 & 5.23 & -0.24 & 4.09 & 3.65 & 1.49 & 2.47 & 1.42 \\
eThekwini & 5.66 & 5.36 & 6.10 & 4.95 & -4.00 & 5.10 & 3.61 & 2.17 & 2.62 & 2.21 & 1.23 \\
uMthlatuze & 5.66 & 5.36 & 6.10 & $9.73-12.94$ & 10.66 & 3.55 & 0.51 & 3.77 & 2.01 & 0.98 \\
\hline
\end{tabular}

Notes Authors' estimations based on data from Statistics South Africa (http://www .statssa.gov.za).

tional provincial regional proxies such as fuel consumption and buildings reported as completed and applying these to the latest national gross domestic product figures (Rossouw 2017). Table 1 indicates the structural relationships between national fuel consumption and regional fuel consumption over the period. The major urban regions of KwaZuluNatal (KZN), which were considered in this study, are eThekwini, Msunduzi and uMthlatuze (previously known as Durban, Pietermaritzburg and Richards Bay, respectively). These structural relationships form the basis of the national disaggregation model from which the regional GDP is estimated.

The equation estimating regional gross domestic product (GDP) using the fuel consumption structure is:

$$
\mathrm{GDP}_{i t}=\mathrm{GDP}_{s t} \times\left[\frac{\sum \frac{P_{i n}}{P_{s n}}}{n}\right],
$$

where $i$ is the particular regional economy/proxy, $s$ national economy/pro$\mathrm{xy} ; t$ the annual period; $n$ the number of national and regional proxies; $P$ national economic proxy, i.e. fuel consumption; $\mathrm{GDP}_{i t}$ is regional gross domestic product at time $t$; and $\mathrm{GDP}_{s t}$ the national GDP at time $t$.

The gross domestic product (growth rate) for each of the three regions is displayed in table 2. The data were generated using equation 7 and are based on the fuel consumption structure as per table 1. 
REGIONAL BUSINESS CONFIDENCE INDICATOR (RBCI)

The business confidence indicator for each of the three regions of KwaZulu-Natal is estimated using a primary survey. The survey for this current study follows the methodology employed by the Bureau of Economic Research (BER). They disseminated a questionnaire annually to a panel of respondents (Bureau for Economic Research 2016). The KZN RBCI does, however, differ from BER's way of dissemination and processing. The surveys are conducted through the various local chambers of commerce and other local business organisations operating in the three urban centres. The survey is an online anonymous business survey designed to generate data and information on several local economic characteristics and trends, and the general level of business confidence in the particular urban centre.

The surveys are conducted annually at the same time to ensure consistency (Kleynhans and Coetzee 2017, 15). The period of investigation was chosen to ensure confidentiality and circumvent ethical issues. In total, a response between 150 and 200 was received annually from the various chambers of commerce and business organisations. The response rate varies between 2 and 5 per cent, depending on the district and the year. It must be said that the response rate is on the low side and as such may not be as reliable as one would ideally want. Nonetheless, the derived confidence indicators do seem to reflect the wider sentiment in that when presenting the results to the wider audience within the districts, there is full agreement with the confidence indicators.

This regional business confidence index (R B CI) is compiled from the percentages of respondents' answers to questions regarding their views on the present business/trading conditions and expected sales over the next year and can be expressed via the following equation:

$$
\mathrm{RBCI}=\left(\frac{\sum B_{i t} C_{i t} G_{i t} H_{i t}}{\sum A_{i t} B_{i t} C_{i t} D_{i t} E_{i t} F_{i t} G_{i t} H_{i t} I_{i t} J_{i t}}\right),
$$

where $i$ is particular local economy; $t$ period; $A_{i t}$ excellent responses to present business/trading conditions are; $B_{i t}=\operatorname{good}$ responses to present business/trading conditions are; $C_{i t}$ fair responses to present business/trading conditions are; $D_{i t}=$ poor responses to present business/trading conditions are; $E_{i t}=$ very poor responses to present business/trading conditions are; $F_{i t}$ much better responses to your expected sales performance over the next year; $G_{i t}$ better responses to expected sales performance for the next year; $H_{i t}$ same responses to expected sales performance for the 
TAB LE 3 Regional Business Confidence Index

\begin{tabular}{lccccccccccc}
\hline Region & 2005 & 2006 & 2007 & 2008 & 2009 & 2010 & 2011 & 2012 & 2013 & 2014 & 2015 \\
\hline Msunduzi & 83.60 & 82.60 & 83.00 & 65.95 & 63.50 & 58.88 & 63.45 & 68.20 & 49.95 & 83.30 & 64.70 \\
eThekwini & 57.10 & 72.80 & 81.09 & 68.13 & 65.75 & 68.50 & 74.95 & 68.55 & 69.65 & 54.20 & 59.70 \\
uMthlatuze & 89.70 & 81.10 & 80.90 & 61.38 & 69.05 & 66.65 & 73.70 & 78.55 & 41.65 & 66.80 & 37.50 \\
\hline
\end{tabular}

NOTES Authors' estimations based on data from Statistics South Africa (http://www .statssa.gov.za).

TABLE 4 Unit Root Statistics for the Panel from 2005 to 2015

\begin{tabular}{lrr}
\hline & RGDP (Y) & RBCI (x) \\
\hline (1) Levin, Lin and Chu t* & $-4.185^{* * *}(0.000)$ & $-9.329^{\star * *}(0.000)$ \\
\hline (2) Im, Pesaran and Shin (2003) W-stat & $-2.535^{\star * *}(0.006)$ & $-6.721^{\star * *}(0.000)$ \\
ADF - Fisher chi-square & $17.723^{\star * \star}(0.007)$ & $36.611^{\star * *}(0.000)$ \\
PP - Fisher chi-square & $28.309^{* * *}(0.000)$ & $38.563^{\star * *}(0.000)$ \\
\hline
\end{tabular}

Notes Row headings are as follows: (1) null: unit root - assumes common unit root process, (2) null: unit root - assumes individual unit root process. $p$-values reported in parenthesis. $p<0.05$ accept the alternative hypothesis of no unit root. ${ }^{* * *}$ indicates significance of the coefficients or rejection of the null hypothesis on a $1 \%$ significance level.

following year; $I_{i t}$ worse responses to expected sales for the coming year; $J_{i t}$ much worse responses to your expected sales performance over the next 12 months.

The regional business confidence index ( $\mathrm{RBCI}$ ) varies between o and 100. Values of 50 are interpreted as neutral, 100 reveals extreme confidence, while o indicates an extreme lack of confidence. The estimated regional business confidence indices ( $\mathrm{RBCI}$ ) for each of the three regions are given in table 3 .

\section{Constructing and Evaluating the Panel}

Figure 1 displays the results from the panel showing the real growth rate of GDP (regional economic growth rate, RGDP) per region ( $y$ variable), and the variance $(\log (r b c i t / r b c i t-1))$ in the regional business confidence index (R в CI) per region ( $x$ variable). The panel consists of three regions (cross-sections) and 11 years (time sections), i.e. 33 observations.

Table 4 displays the outcomes of the panel unit root test for the two variables. It suggests that the variables are stationary, i.e. I(o). As stated previously, the panel does, unfortunately, suffer from a lack of crosssection (regions) data, which poses some risks; for example, the model 
durb - GDP

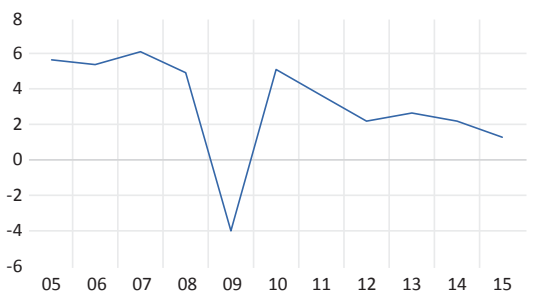

rbay - GDP
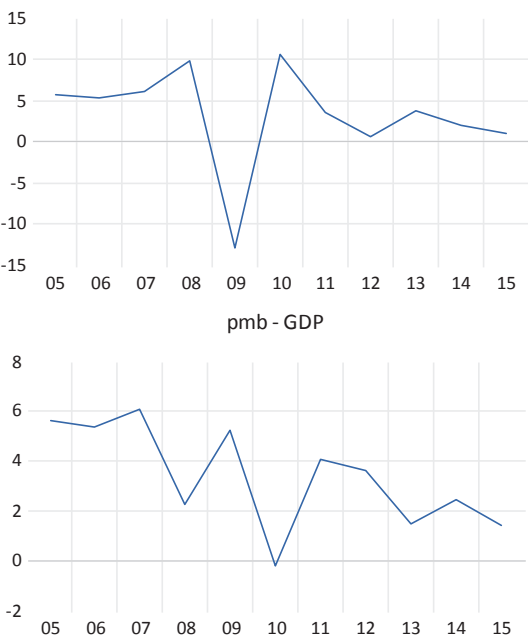

durb - VRBCI

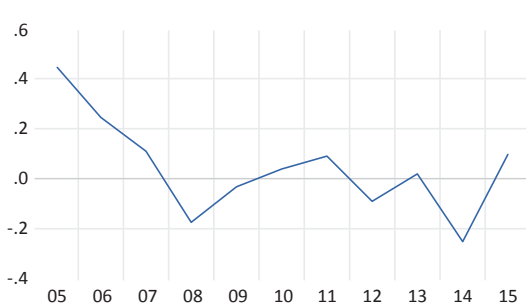

rbay-VRBCI
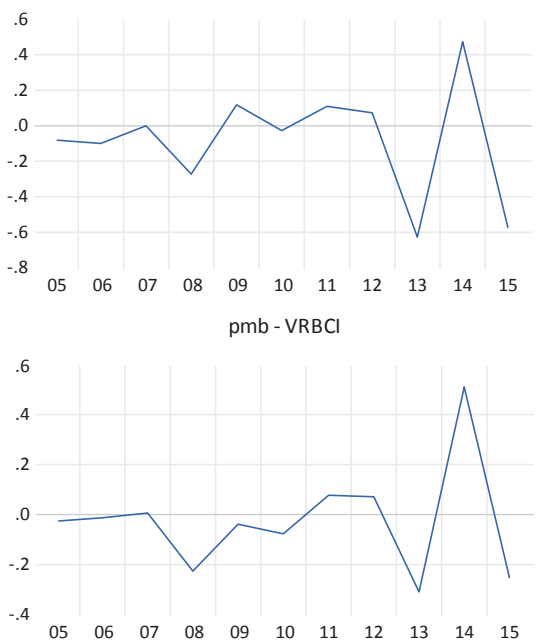

FIGURE 1 Panel for the Three Regions 2005 to 2015

NOTES durb $=$ eThekwini, $\mathrm{pmb}=$ Msunduzi, rbay $=$ uMhlatuze, GDP $=$ regional growth rate, $\mathrm{VRBCI}=\log$ variance in regional business confidence index, $y$-axis $=$ percentage in the case of GDP and log value in the case of VRBCI, $x$-axis = year; authors' estimations based on data from Statistics South Africa (http://www.statssa.gov.za).

may potentially suffer from misspecification bias, poor fit and statistical insignificance. The Granger causality tests also yield few significant results. These are important issues that should be addressed in further research once this article has illustrated the value of the R B CI's potential. These constraints should, however, not detract from the potential use of business confidence indicators, especially if and when the data limitations have been addressed.

\section{Methodology of Analysis}

Mitić, Ivanović, and Zdravković (2017) suggest the use of panel econometric modelling for the estimation of the interdependency between vari- 
ables. To this end, panel cointegration tests strive to provide more reliable results in testing of cointegration presence relative to those obtained by individual tests. The most frequently used panel cointegration tests are based on unit root testing of residuals from the oLs-wise regression, known in the literature under the umbrella term of the 'Engle-Granger based' (EG) cointegration test. The broadest framework for a panel cointegration test based on the EG procedure was proposed by Pedroni (1999).

Following from the above, the methodology employed in this study follows the methodology employed by Kirikkaleli et al. (2018) and Srithilat et al. (2018). Kirikkaleli et al. (2018) studied the long-run linkage between the electricity consumption, economic growth and internet demand variables for OECD countries using panel cointegration tests, while Srithilat et al. (2018) studied the relationship between inflation, exchange rate, and currency substitution following the panel vector error correction model approach. The methodology follows that for the same order of integration (I(o) or I(1)) variables; cointegration linkage is investigated following the panel unit root test procedure (table 4). As stated by Pedroni (1999), the Pedroni cointegration test is based on pooling among both within dimensions and between dimensions. Pedroni (2001) has developed statistics that are based on pooling among dimensions, which will allow for heterogeneity in the autoregressive term (Kirikkaleli 2016, 213). The equation for Pedroni (2001) cointegration tests can be written as follows:

$$
\operatorname{RGDP}_{i t}=\alpha_{i}+\varphi_{i t}+\beta_{1} \mathrm{RBCI}_{i t}+\varepsilon_{i t},
$$

where $i=1, \ldots, N$ for each region in the panel and $t=1, \ldots, T$ refers to the time period. The parameters $\alpha_{i}$ and $\alpha_{i t}$ allow for the possibility of region-specific fixed effects and deterministic trends, respectively. The cointegration tests involve computing residuals from equation (9) and then using the residuals to test the presence of a unit root. The residual equation is given by:

$$
\varepsilon_{i t}=\rho \varepsilon_{i t}-1+v_{t} .
$$

As proposed by Oche, Khamfula, and Mah (2019) and Srithilat et al. (2018), following the panel cointegration test, the study will also estimate a vector error correction model:

$$
\begin{gathered}
\Delta y_{i t}=\alpha_{i} \beta_{i} y_{i, t}-1+\sum_{j=1}^{p i-1} \Gamma_{i j} \Delta y_{i, t}-j+Z_{i} d_{t}+\varepsilon_{i t}, \\
t=1, \ldots, T, i=1, \ldots, N .
\end{gathered}
$$


where $t$ and $i$ are indexes of time dimension and cross-section, respectively, while $\varepsilon_{i t}$ is an error term assumed to be distributed independently. The process $y_{i t}$ of $K$-dimension is at most integrated of order one; that is, $\mathrm{I}(1)$ with a cointegrating rank of $\mathrm{o} \leq r_{i} \leq K$. The unknown $\left(K \times r_{i}\right)$ and $\alpha_{i}$ and $\beta_{i}$ are the loading and the cointegrating matrices, respectively, and they have full column rank. $p i-1$, is the lag order of the vector error correction (VEC) process and is either different across the cross-section or controlled to be constant (Shrestha and Bhatta 2018).

The short-run dynamics of the process are represented by the unknown coefficient matrices denoted as $\Gamma_{i j}, i=1, \ldots, N ; j=1, \ldots, p i-1$, while the long-run dynamics are represented as $\Pi_{i}=\alpha_{i} \beta_{i}, i=1, \ldots, N$. $Z_{i}$ is the unknown parameter vector of the deterministic terms, while the $d t$ vector contains the deterministic terms (Shrestha and Bhatta 2018).

It is further suggested (Mark and Sul 2003), for panel cointegration, that fully modified ordinary least squares (F MOLS) and dynamic ordinary least squares (DOLS) tests are applied to determine the long-run connection between variables. This methodology is further supported by Mitić, Ivanović, and Zdravković (2017) through their analysis of the relationship between real GDP and $\mathrm{CO}_{2}$ emissions for 17 transitional economies. Endogeneity bias and serial correlations are corrected by FMOLS and DOLS techniques and therefore these estimators allow for standard normal inference (Carlsson, Lyhagen, and Österholm 2007).

The panel cointegration methodology will be augmented with the auto-regressive distributed lag (ARDL) methodology, predominantly to verify the results of the applied panel models. Asteriou, Pilbeam, and Pratiwi (2021) employed the asymmetric panel ARDL method to analyse the impact of a change in public debt on economic growth in a panel of selected Asian countries from 1980 through 2012. Asteriou, Pilbeam, and Pratiwi (2021) state that it is indeed possible to examine the short- and long-run relationships using the panel ARDL as initiated by Pesaran and Smith (1995) and Pesaran, Shin, and Smith (1999). Panel autoregressive distributed lag (ARDL) is conducted if no-cointegration is found from the previous methods. This method is superior regardless of whether the underlying regressors exhibit I(O), I(1) or a mixture of both (Pesaran and Shin 1995).

Ghouse, Khan, and Rehman (2018) state that the dependent variable of an ARDL model is expressed by the lag and current values of the independent variable and its lag. The ARDL model normally starts from a reasonably general and large dynamic model and progressively reduc- 
ing its mass and altering variable by imposing linear and non-linear restrictions (Charemza and Deadman 1997). The ARDL model is one of the most general dynamic unrestricted models in econometric use (Shrestha and Bhatta 2018).

A generalised ARDL $(p, q)$ model is specified as:

$$
Y_{t}=\gamma \mathrm{o}_{j}+\sum_{i=1}^{p} \delta_{j} Y_{t}-1+\sum_{i=0}^{q} \beta_{j} X_{t}-1+\varepsilon_{j t},
$$

$p \geq 1$, for simplicity, assumes that the lag order $q$ is the same for all variables in the $K \times 1$ vector $x_{t} . \delta$ is a coefficient, $\gamma$ is the constant and $\varepsilon_{j t}$ is a vector of the error terms. $Y_{t}$ is the regional GDP (RGDP) at period $t$ and $X_{t}$ is the variance in regional business confidence (RBCI).

\section{Econometric Analysis of the Panel}

Following the methodologies employed by Mark and Sul (2003), Kirikkaleli et al. (2018) and Asteriou, Pilbeam, and Pratiwi (2021), two cointegration tests are conducted to analyse the long-run relationship between regional economic growth and regional business confidence. The results of the Pedroni cointegration test (automatic lag selection using the Schwarz info criterion) are displayed in table 5. The outcome of the Pedroni panel cointegration indicates that eight out of 11 statistics in model 1 , six out of 11 statistics in model 2, and seven out of 11 statistics in model 3 are significant at the $5 \%$ level. This suggests that the no cointegration null hypothesis for all models can be rejected. The panel statistics assume common A R (autoregressive) coefficients (within dimensions), while the group statistics assume individual A R coefficients (between dimensions).

The findings from the Kao panel cointegration test for all models are in line with the findings from the Pedroni panel cointegration test as shown in table 5 (ADF statistic is minus 1.615123 with a $p$-value of $0.0531^{\star *}$ ). Therefore, both results confirm the existence of a long-run cointegration relation between regional economic growth and regional business confidence.

The Fisher-Johansen cointegration test (intercept and trend) results are displayed in table 6 , indicating that the no cointegration null hypothesis can be rejected.

Given the existence of a cointegrating relationship between RGDP and $\mathrm{RBCI}$ (tables 5 and 6), it is possible to estimate the panel vector error correction model as suggested by Oche (2019). The results are displayed in table 7 . The results suggest that the long-run coefficient (12.67178) is sta- 
TABLE 5 Results of the Pedroni cointegration test (RGDP and RBCI)

\begin{tabular}{|c|c|c|c|c|c|}
\hline & & (1) & (2) & (3) & (2) \\
\hline \multirow[t]{7}{*}{ Model 1} & Panel v-Statistic & -1.033451 & 0.8493 & -0.8785 & 0.8102 \\
\hline & Panel rho-Statistic & -1.945918 & $0.0258^{* * *}$ & -1.6602 & $0.0484^{* * *}$ \\
\hline & Panel pP-Statistic & -8.650277 & $0.0000^{* * *}$ & -6.2958 & $0.0000^{* * *}$ \\
\hline & Panel ADF-Statistic & -5.705665 & $0.0000^{* * *}$ & -4.7942 & $0.0000^{* * *}$ \\
\hline & Group rho-Statistic & -0.566669 & 0.2855 & & \\
\hline & Group PP-Statistic & -7.325659 & $0.0000^{* * *}$ & & \\
\hline & Group ADF-Statistic & -4.656979 & $0.0000^{* * *}$ & & \\
\hline \multirow[t]{7}{*}{ Model 2} & Panel v-Statistic & -2.336323 & 0.9903 & -2.1350 & 0.9836 \\
\hline & Panel rho-Statistic & -0.558121 & 0.2884 & -0.4622 & 0.3219 \\
\hline & Panel pp-Statistic & -18.56025 & $0.0000^{* * *}$ & -15.1930 & $0.0000^{* * *}$ \\
\hline & Panel ADF-Statistic & -4.531988 & $0.0000^{* * *}$ & -4.9101 & $0.0000^{* * *}$ \\
\hline & Group rho-Statistic & 0.244963 & 0.5968 & & \\
\hline & Group PP-Statistic & -15.69201 & $0.0000^{* * *}$ & & \\
\hline & Group ADF-Statistic & -5.58721 & $0.0000^{* * *}$ & & \\
\hline \multirow[t]{7}{*}{ Model 3} & Panel v-Statistic & -0.540941 & 0.7057 & -0.673866 & 0.7498 \\
\hline & Panel rho-Statistic & -2.329033 & $0.0099^{\star * *}$ & -1.168057 & 0.1214 \\
\hline & Panel pp-Statistic & -3.124649 & $0.0009^{* * *}$ & -2.049121 & $0.0202^{* * *}$ \\
\hline & Panel ADF-Statistic & -3.216785 & $0.0006^{* * *}$ & -2.205183 & $0.0137^{* * *}$ \\
\hline & Group rho-Statistic & -0.168863 & 0.4330 & & \\
\hline & Group PP-Statistic & -2.386564 & $0.0085^{\star * *}$ & & \\
\hline & Group ADF-Statistic & -2.460465 & $0.0069^{* * *}$ & & \\
\hline
\end{tabular}

NOTES Column headings are as follows: (1) statistic, (2) probability, (3) weighted statistic. ${ }^{* *}$ denotes $10 \%$ significance level.

TABLE 6 Results of the Fisher-Johansen Cointegration Test

\begin{tabular}{lrlll}
\hline Hypothesised no. of $\mathrm{CE}(\mathrm{s})$ & $(1)$ & \multicolumn{1}{c}{$(2)$} & $(3)$ & $(2)$ \\
\hline None & 21.32 & $0.0016^{* * *}$ & 15.01 & $0.0202^{* * *}$ \\
At most 1 & 11.96 & 0.0628 & 11.96 & 0.0628 \\
\hline
\end{tabular}

NOTES Column headings are as follows: (1) Fisher statistics (from trace test), (2) probability, (3) Fisher statistics (from max-eigen test); ${ }^{* \star *}$ denotes $10 \%$ significance level.

tistically significant, as well as the error correction term (-0.958025). The short-run lag 1 period coefficient (12.21207) is also statistically significant. The results suggest that there is indeed long-run causality running from 
TABLE 7 Results of the Panel Vector Error Correction Model

\begin{tabular}{|c|c|c|c|}
\hline Cointegrating eq. & Cointegrating eq. 1 & Error correction & $\mathrm{D}(\mathrm{GDP})$ \\
\hline \multirow[t]{3}{*}{$\operatorname{RGDP}(-1)$} & 1 & Error Term & $-0.95803^{\star *}$ \\
\hline & & & $(-0.46888)$ \\
\hline & & & {$[-2.04320]$} \\
\hline \multirow[t]{3}{*}{$\mathrm{RBCI}(-1)$} & $12.67180^{* * *}$ & $\mathrm{D}(\operatorname{RGDP}(-1))$ & -0.38709 \\
\hline & $(-3.90616)$ & & $(-0.37890)$ \\
\hline & {$[3.24405]$} & & {$[-1.02163]$} \\
\hline \multirow[t]{12}{*}{$\mathrm{C}$} & -2.71359 & $\mathrm{D}(\operatorname{RGDP}(-2))$ & -0.25857 \\
\hline & & & $(-0.22207)$ \\
\hline & & & {$[-1.16436]$} \\
\hline & & $\mathrm{D}(\mathrm{RBCI}(-1))$ & $12.21207^{* *}$ \\
\hline & & & $(-4.72176)$ \\
\hline & & & {$[2.58634]$} \\
\hline & & $\mathrm{D}(\mathrm{RBCI}(-2))$ & 9.06565 \\
\hline & & & $(-6.46707)$ \\
\hline & & & {$[1.40182]$} \\
\hline & & $\mathrm{C}$ & -0.69075 \\
\hline & & & $(-0.98862)$ \\
\hline & & & {$[-0.69870]$} \\
\hline
\end{tabular}

NOTES ${ }^{* * *}$ denotes $10 \%$ significance level; standard errors in (), $t$-statistics in [].

RBCI to RGDP and that there is an adjustment process to long-run equilibrium (negative error correction term).

The vector error correction model (as displayed in table 7) can be expressed as follows:

$$
\begin{aligned}
\mathrm{D}(\mathrm{RGDP})= & \mathrm{C}(1) \times(\operatorname{RGDP}(-1)+12.671798474 \times \mathrm{RBCI}(-1) \\
& -2.71359215585)+\mathrm{C}(2) \times \mathrm{D}(\operatorname{RGDP}(-1)) \\
& +\mathrm{C}(3) \times \mathrm{D}(\operatorname{RGDP}(-2))+\mathrm{C}(4) \times \mathrm{D}(\operatorname{RBCI}(-1)) \\
& +\mathrm{C}(5) \times \mathrm{D}(\operatorname{RBCI}(-2))+\mathrm{C}(6),
\end{aligned}
$$

where $\mathrm{C}(1)$ is error correction term $-0.958025, \mathrm{C}(2)$ short-run RGDP lag 1 term $-0.387093, \mathrm{C}(3)$ short-run RGDP lag 2 term -0.258572 , C(4) shortrun RBCI lag 1 term 12.21207, C(5)short-run RBCI lag 2 term 9.065647, C(6) short-run constant term -0.690752 .

Table 8 illustrates the outcomes of the FMOLS and DoLs estimates for 
TABLE 8 Panel FMOLS and DOLS results

\begin{tabular}{lllrr}
\hline & & & Coefficient & Probability \\
\hline$Y=$ RGDP FMOLS & Constant & RBCI & 1.358957 & 0.4213 \\
& Linear Trend & RBCI & 0.406644 & 0.8001 \\
& None & RBCI & 0.075009 & 0.9866 \\
\hline Y= RGDP DOLS & Constant & RBCI & 1.298782 & 0.5306 \\
& Linear Trend & RBCI & 0.301675 & 0.8629 \\
& None & RBCI & 1.017768 & 0.8239 \\
\hline
\end{tabular}

TABLE 9 Results of the ARDL model

\begin{tabular}{llrrrr}
\hline Equation & Variable & Coefficient & Std. error & $t$-statistic & $p$-value \\
\hline Long Run & RBCI $(-1)$ & 7.634437 & 2.888130 & 2.64338 & $0.0145^{* * *}$ \\
\hline Short Run & COINTEQ01 & -1.195213 & 0.227691 & -5.24928 & $0.0000^{* * *}$ \\
& D(RBCI $(-1))$ & -6.754286 & 3.181049 & -2.12328 & $0.0447^{* * *}$ \\
& C & 3.758449 & 0.754256 & 4.98298 & $0.0000^{* * *}$
\end{tabular}

NOTES ${ }^{* * \star}$ denotes $1 \%$ significance level.

the three models (panel method = grouped). The findings are particularly consistent with existing literature in that the models suggest positive relationships between RGDP and RBCI. However, the models could not find the relationships as statistically significant in the long run. This is contrary to the results thus far obtained and can possibly be explained because of model-specific limitations such as the lack of cross-sections to perform the FMOLS and DOLS estimates.

The ARDL model results are displayed in table 9. Estimating the generalised ARDL model (equation 9) suggests the use of an ARDL $(1,1)$ model. The optimal lag structure was derived from the Akaike Information Criteria (AIC). It suggests that there exists both a short-run and long-run relationship between regional business confidence (RBCI) and regional economic growth (RGDP). The error correction term (COINTEQO1) is -1.19 with a $p$-value of 0.000 , suggesting that the co-integration coefficient is statistically significant. Furthermore, the long-run coefficient (7.634437) is statistically significant, as well as the short-run lag 1 period coefficient $(-6.753185)$.

The cross-section short-run coefficients using ARDL are displayed in table 10. For each of the three regions, the error correction terms (COINTEQO1) are statistically significant, suggesting that there is indeed long- 
TAB LE 10 Cross Section Short Run Coefficients

\begin{tabular}{llrrrr}
\hline Region & Variable & Coefficient & Std. error & $t$-statistic & $p$-value \\
\hline eThekwini & COINTEQ01 & -1.494570 & 0.080925 & -18.468510 & $0.0003^{* * *}$ \\
& D(RBCI $(-1))$ & -0.015055 & 0.004018 & -3.746534 & $0.0332^{* * *}$ \\
& C & 4.270804 & 0.934469 & 4.570302 & $0.0197^{* * *}$ \\
Msunduzi & COINTEQ01 & -1.051115 & 0.084246 & -12.476800 & $0.0011^{* * *}$ \\
& D(RBCI $(-1))$ & -0.104839 & 0.001339 & -78.308750 & $0.0000^{* * *}$ \\
& C & 3.747103 & 1.539497 & 2.433978 & $0.0930^{* * *}$ \\
uMhlathuze & COINTEQ01 & -1.543835 & 0.090992 & -16.966740 & $0.0004^{* * *}$ \\
& D(RBCI $(-1))$ & -0.102348 & 0.004008 & -25.532780 & $0.0001^{* * *}$ \\
& C & 5.677368 & 5.128576 & 1.107007 & 0.3491 \\
\hline
\end{tabular}

NOTES ${ }^{\star * \star}$ Denotes $1 \%$ significance level.

run causality running from $\mathrm{RBCI}$ to RGDP and that there is an adjustment process to long-run equilibrium (negative error correction term) for each of the three regions.

\section{Conclusions}

The association between regional business confidence and regional real GDP growth was estimated in this article using panel data methodology and estimation techniques, in an attempt to account for both time and region heterogeneity and homogeneity. The estimation ability of the suggested model exhibits good statistical qualities, yielding significant estimations of regional economic activity.

The techniques enable sub-regional GDP analysis and take sub-regional heterogenic factors into regard when estimating regional economic activity. This includes unobservable region-specific factors. The method of estimation also considered time-series and cross-section dimensions of the data, which improve the quality of the estimated relevant coefficient, as the degrees of freedom were improved when these estimation techniques were employed.

Given the limited panel data, i.e. a limited number of cross-sections, these estimates need further investigation. Nonetheless, the estimation results suggest that, on grounds of the range of specifications applying econometric panel data techniques, regional business confidence and regional real GDP growth rates display some positive relationships. It is therefore concluded that business confidence can be utilised as an early indicator of real regional gross domestic economic growth. Therefore, the 
key fundamental reason for the study, i.e. to fill the data asymmetry that exists at the sub-national level in SA, has been addressed.

The value of $\mathrm{BCI}$ as an early indicator of economic indicators has been substantiated in this article. The estimation method has been developed, as well as its potential proven motivation for further research. The proposed method should now be applied in practice by managers, and development and policy designers, both nationally and sub-regionally. The estimation of GDP using B C I should now be expanded to other provinces and cities, as well as neighbouring countries. The relationship between countrywide BCI of BER and the national GDP should also be investigated using a similar methodology.

\section{Acknowledgments}

The authors acknowledge the support from the World Trade Organization (w to) and the National Research Foundation (NRF). The findings, views and opinions expressed, and conclusions arrived at in this article, are those of the authors and should not necessarily be attributed to the funding institutions.

\section{References}

Asteriou, D., K. Pilbeam, and C. E. Pratiwi. 2021. 'Public Debt and Economic Growth: Panel Data Evidence for Asian Countries.' Journal of Economics and Finance 45 (2): 270-87.

Bank of Albania. 2018. Modelling the Quarterly GDP: Role of Economic and Surveys Indicators. Tirana: Bank of Albania.

Benkovskis, K. 2008. 'Short-Term Forecasts of Latvia's Real Gross Domestic Product Growth Using Monthly Indicators.' Working Paper 5-2008, Latvijas Banka, Riga.

Binette, A., and J. Chang. 2013. CsI: A Model for Tracking Short-Term Growth in Canadian Real GDP. Ottawa: Bank of Canada.

Binge, L. H. 2020. 'Business Confidence and the Business Cycle in South Africa.' In Business Cycles and Structural Change in South Africa, edited by W. H. Boshoff. 237-63. Cham: Springer.

Bureau for Economic Research. 2016. 'Business and Consumer Surveys.' https://www.ber.ac.za/About-BER/Product-offering/Surveys/Surveys -Method/

Carlsson, M., J. Lyhagen, and P. Österholm. 2007. 'Testing for Purchasing Power Parity in Co-Integrated Panels.' IMF Working Paper w P/o7/287, International Monetary Fund, Washington, D C.

Charemza, W. W., and D. F. Deadman. 1997. New Directions in Econometric Practice. 2nd ed. Cheltenham: Edward Elgar. 
Chow, G. C., and A. Lin. 1971. 'Best Linear Unbiased Interpolation, Distribution, and Extrapolation of Time Series by Related Series.' Review of Economics and Statistics 53 (4): 372-5.

Coetzee, C. E., and E. P. J. Kleynhans. 2017. 'Public Capital Stock and Economic Growth: A KwaZulu-Natal Case Study'. South African Journal of Economic and Managerial Sciences 20 (1): a1591.

Curtin, R. T. 2000. 'Psychology and Macroeconomics: Fifty Years of the Surveys of Consumers.' Special Report, University of Michigan.

Dées, S., and P. S. Brinca. 2013. 'Consumer Confidence As a Predictor of Consumption Spending.' International Economics 134:1-14.

De Mello, E. P. G., and F. M. R. Figueiredo. 2014. 'Assessing the Short-term Forecasting Power of Confidence Indices.' Working Paper Series 371, Banco Central do Brasil, Brasilia.

Diron, M. 2008. 'Short-Term Forecasts of Euro Area Real GDP Growth.' Journal of Forecasting 27 (5): 371-90.

Easaw, J. Z., and S. M. Heravi, 2004. 'Evaluating Consumer Sentiments as Predictors of $\mathrm{UK}$ Household Consumption Behaviour: Are They Accurate and Useful?' International Journal of Forecasting 20 (4): 671-81.

European Central Bank. 2003. 'Can Confidence Indicators Be Useful to Predict Short Term Real GDP Growth?' Working Paper 133, European Central Bank, Frankfurt.

- 2006. 'Short-Term Forecasts of Euro Area Real GDP Growth: An Assessment of Real-Time Performance Based on Vintage Data.' Working Paper 622, European Central Bank, Frankfurt.

Gossman, K. A., and M. G. Hayes. 2018. 'An Investigation into the Ability of the Reverse Yield Gap to Forecast Inflation And Economic Growth in South Africa.' South African Journal of Economic and Management Sciences 21 (1): 1-13.

Ghouse, G., S. A. Khan, and A. U. Rehman. 2018. 'A RDL Model As a Remedy for Spurious Regression: Problems, Performance and Prospectus.' MPR A Paper 83973, Munich Personal RePEc Archive.

Im, K. S., M. H. Pesaran, and Y. Shin. 2003. 'Testing for Unit Roots in Heterogeneous Panels.' Journal of Econometrics 115 (1): 53-74.

Kirikkaleli, D. 2016. 'Interlinkage Between Economic, Financial, and Political Risks in the Balcan Countries: Evidence from a Panel Cointegration.' Eastern European Economics 54 (3): 208-27.

Kirikkaleli, D., S. Sokri, M. Candemir, and H. M. Ertugrul. 2018. 'Panel Cointegration: Long-Run Relationship between Internet, Electricity Consumption and Economic Growth; Evidence from OECD countries.' Investigación Económica 77 (303): 161-76.

Kleynhans, E. P. J., and C. E. Coetzee. 2017. 'The Influence of Space on Business Confidence.' Africa Growth Agenda 14 (1): 15-7. 
Kwan, A. C., and J. A. Cotsomitis. 2006. 'The Usefulness of Consumer Confidence in Forecasting Household Spending in Canada: A National and Regional Analysis.' Economic Inquiry 44 (1): 185-97.

Ludvigson, S. C. 2004. 'Consumer Confidence and Consumer Spending.' Journal of Economic Perspectives 18 (2): 29-50.

Mark, N. C., and D. Sul. 2003. 'Cointegration Vector Estimation by Panel Dols and Long-Run Money Demand. Oxford Bulletin of Economics and Statistics 65 (5): 655-80.

Mitchell, J., R. J. Smith, M. R. Weale, S. Wright, and E. L. Salazar. 2005. 'An Indicator of Monthly GDP and an Early Estimate of Quarterly GDP Growth.' Economic Journal 115 (501): F108-29.

Mitić, P., O. M. Ivanović, and A. Zdravković. 2017. 'A Cointegration Analysis of real GDP and $\mathrm{CO}_{2}$ Emissions in Transitional Countries.' Sustainability 9 (4): 1-18.

Mourougane, A., and M. Roma. 2003. 'Can Confidence Indicators be Useful to Predict Short Term Real GDP Growth?' Applied Economics Letters 10 (8): 519-22.

Oche, M. O., Y. Khamfula, and G. Mah. 2019. 'The Effect of Financial Crises on Growth and FDI in Some African Countries: A Panel vecm Approach.' Journal of Reviews on Global Economics 8:1308-19.

Pedroni, P. 1999. 'Critical Values for Cointegration Tests in Heterogeneous Panels with Multiple Regressors.' Oxford Bulletin of Economics and Statistics 61 (s1): 653-70.

- 2001. 'Purchasing Power Parity Tests in Cointegrated Panels.' Review of Economics and Statistics 83 (4): 727-31.

Pesaran, M. H., and R. P. Smith. 1995. 'Estimating Long-Run Relationships from Dynamic Heterogeneous Panels.' Journal of Econometrics 68 (1): 79-113.

Pesaran, M. H., Y. Shin. 1995. 'An Autoregressive Distributed-Lag Modelling Approach to Cointegration Analysis.' Cambridge Working Papers in Economics 9514, University of Cambridge.

Pesaran, M. H., Y. Shin, and R. P. Smith. 1999. 'Pooled Mean Group Estimation of Dynamic Heterogeneous Panels.' Journal of the American Statistical Association 94 (446): 621-34.

Polasek, W. 2009. Bayesian and Classical Methods for Completing Disaggregated Data: The Spatial Chow-Lin Approach. Paris: oECD.

Porter, M. E. 2003. 'The Economic Performance of Regions'. Regional Studies $37(6-7): 549-78$.

Rossouw, S. 2017. 'Measuring the Vulnerability of Sub-National Regions: Integrating Relative Location.' South African Journal of Economic and Management Sciences 20 (1): 1-15.

Santero, T., N., and Westerlund. 1996. 'Confidence Indicators and Their 
Relationship to Changes in Economic Activity'. Working Paper 170, OECD, Paris.

Shrestha, M. B., and G. R. Bhatta. 2018. 'Selecting Appropriate Methodological Framework for Time Series Data Analysis.' Journal of Finance and Data Science 4 (2): 71-89

Srithilat. K., G. Sun, T. Chanthanivong, and M. Thavisay. 2018. 'The Relationship between Inflation, Exchange Rate, and Currency Substitution: Evidence from Panel Vector Error Correction Model Approach.' International Journal of Economics and Financial Issues 8 (2): 79-84.

Vidoli, F., and C. Mazziotta. 2012. 'Spatial Composite and Disaggregate Indicators: Chow-Lin Methods and Applications.' Territorio Italia: Land Administration, Cadastre, Real Estate, no. 2: 9-19.

Wilcox, J. A. 2007. 'Forecasting Components of Consumption with Components of Consumer Sentiment.' Business Economics 42 (4): 22-32. 